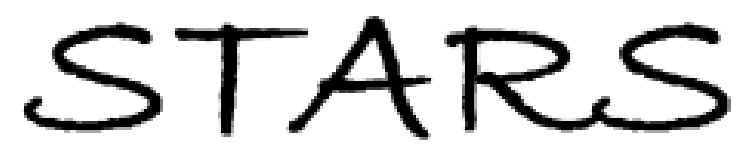

University of Central Florida

STARS

$1-1-2005$

\title{
High dose Co-60 gamma irradiation of InGaN quantum well light- emitting diodes
}

Rohit Khanna

Sang Youn Han

S. J. Pearton

D. Schoenfeld

W. V. Schoenfeld

University of Central Florida

See next page for additional authors

Find similar works at: https://stars.library.ucf.edu/facultybib2000

University of Central Florida Libraries http://library.ucf.edu

This Article is brought to you for free and open access by the Faculty Bibliography at STARS. It has been accepted for inclusion in Faculty Bibliography 2000s by an authorized administrator of STARS. For more information, please contactSTARS@ucf.edu.

\section{Recommended Citation}

Khanna, Rohit; Han, Sang Youn; Pearton, S. J.; Schoenfeld, D.; Schoenfeld, W. V.; and Ren, F., "High dose Co-60 gamma irradiation of InGaN quantum well light-emitting diodes" (2005). Faculty Bibliography 2000s. 5343.

https://stars.library.ucf.edu/facultybib2000/5343

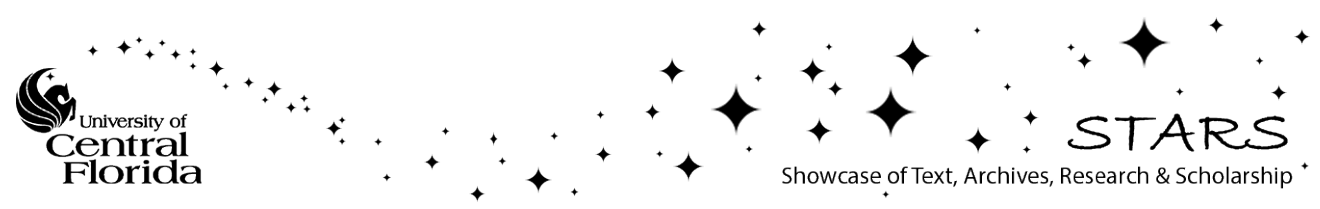




\section{Authors}

Rohit Khanna, Sang Youn Han, S. J. Pearton, D. Schoenfeld, W. V. Schoenfeld, and F. Ren 


\title{
High dose Co-60 gamma irradiation of InGaN quantum well light-emitting diodes
}

\author{
Rohit Khanna, Sang Youn Han, and S. J. Pearton \\ Department of Materials Science and Engineering, University of Florida, Gainesville, Florida 32611 \\ D. Schoenfeld \\ Department of Nuclear and Radiological Engineering, University of Florida, Gainesville, Florida 32611 \\ W. V. Schoenfeld \\ CREOL, University of Central Florida, Orlando, Florida 32816 \\ F. Ren \\ Department of Chemical Engineering, University of Florida, Gainesville, Florida 32611
}

(Received 23 May 2005; accepted 19 September 2005; published online 16 November 2005)

\begin{abstract}
InGaN multiquantum-well light-emitting diodes (LEDs) in the form of unpackaged die with emission wavelengths from 410 to $510 \mathrm{~nm}$ were irradiated with ${ }^{60} \mathrm{Co} \gamma$-rays with doses in the range 150-2000 Mrad (Si). The forward turn-on voltage for all the irradiated LEDs was increased slightly (e.g., by only $\sim 0.1-0.15 \mathrm{~V}$ for $500 \mathrm{MRad}$ dose irradiation) while the reverse breakdown voltage was unchanged within experimental error. The light output intensity for the $410 \mathrm{~nm}$ diodes was decreased by $20 \%$ after a dose of $150 \mathrm{MRad}$ and $75 \%$ after $\sim 2$ GRad. The current transport in the LEDs was dominated by generation-recombination (ideality factor $\sim 2$ ) both before and after irradiation. The morphology and appearance of the $p$ and $n$-Ohmic metallization did not show any detectable change as a result of even the highest $\gamma$-ray dose. (C) 2005 American Institute of Physics.
\end{abstract} [DOI: $10.1063 / 1.2132085]$

There continues to be strong interest in the development of $\mathrm{GaN} / \mathrm{InGaN}$ multiquantum well (MQW) light-emitting diodes (LEDs). ${ }^{1-8}$ These are commercially available in a broad range of visible wavelengths for use in applications including architectural and stage lighting, indoor and outdoor accent lighting, traffic and railway signaling, commercial and retail signs and displays, outdoor illumination and traffic lights. There is also interest in shorter wavelength LEDs with high $\mathrm{Al}$ content $\mathrm{AlGaN}$ active regions, for use in emerging bioremediation and detection systems. ${ }^{7,9,20}$ One of the most promising applications for nitride LEDs is solid state lighting (SSL), where color-combining of red, green, and blue LEDs or pumping of phosphors can be used for general illumination. ${ }^{7-20}$ There is a $\$ 12$ billion-a-year market for sources of white light, including light bulbs and fluorescent tubes. ${ }^{21}$ There is also strong interest in the effects of directly or indirectly ionizing radiation on nitride-based devices, for space-based applications and radiation-monitoring. ${ }^{22-28}$ In this situation, a premium is placed on radiation-resistance. InGaN/GaN light-emitting devices showed only small changes $(<10 \%)$ in their electrical characteristics for 2-40 MeV proton irradiation at doses equivalent to 100 years in low-earth orbit ${ }^{24}$ and to neutron and energetic electron fluxes, ${ }^{25-28}$ although the optical output intensity was more significantly degraded. For many applications, a decrease in light output intensity of up to a factor of 2 as a result of irradiation is acceptable. In general, $\mathrm{GaN}$ is reported to be 2-3 orders of magnitude more resistant than GaAs to decreases in its luminescence due to proton or electron irradiation. $^{24,25,27,28}$ This is a result of the higher displacement threshold energy (Td) in GaN. ${ }^{25}$

In this letter, we report on the effect of Co-60 $\gamma$-rays on GaN/InGaN MQW LEDs at very high doses of up to $\sim 2 \mathrm{GRad}(\mathrm{Si})$. Exposure of semiconductor devices to gamma ray fluxes can produce displacement damage and eventual device failure. Minority carrier devices such as LEDs that rely on carrier lifetime for their operation are expected to be the most sensitive to radiation damage. The behavior of neutral radiation like gamma rays passing through semiconductors is fundamentally different than the interaction with charged particles such as protons, electrons or alpha particles and the energy loss mechanisms are the photoelectric effect, Compton scattering and pair production. We find that unpackaged InGaN/GaN LEDs with emission wavelengths in the range $410-510 \mathrm{~nm}$ are still operational after exposure to very large doses $[\sim 2 \mathrm{GRad}(\mathrm{Si})]$ of Co-60 $\gamma$ rays, showing that these devices are indeed radiation-hard and that other issues such as degradation of the epoxy lens will likely be more important in high $\gamma$-ray flux environments.

The GaN LEDs were commercial unpackaged bare die from UniRoyal Optoelectronics with four different emission wavelengths, namely 410, 445, 465, and $510 \mathrm{~nm}$. The maximum output powers were $3 \mathrm{~mW}$ in the first three cases and $1.6 \mathrm{~mW}$ in the final case. The forward voltages (defined as the voltage at which the current density is $50 \mathrm{~mA} / \mathrm{cm}^{2}$ ) were $\sim 3.3 \mathrm{~V}$ for the 410,445 , and $465 \mathrm{~nm}$ devices and $\sim 3.1 \mathrm{~V}$ for the $510 \mathrm{~nm}$ devices. The epitaxial structures with multiple undoped InGaN multiquantum wells and $n$ - and $p$-type GaN cladding layers were grown by metal organic chemical vapor deposition on sapphire substrates. Figure 1 shows an optical microscope image of one of these dies. The die size was $100 \times 100 \mu \mathrm{m}$, while the $p$-contact diameter was $40 \mu \mathrm{m}$. The devices were exposed to a $600 \mathrm{Ci}{ }^{60} \mathrm{Co}$ source for accumulated doses up to $2.04+/-0.1 \mathrm{Mrad}$. The die were not in operation during the radiation exposure. The calibration of dose was performed with radioactive films and ion chamber radiation meters. The absorption depth of the 


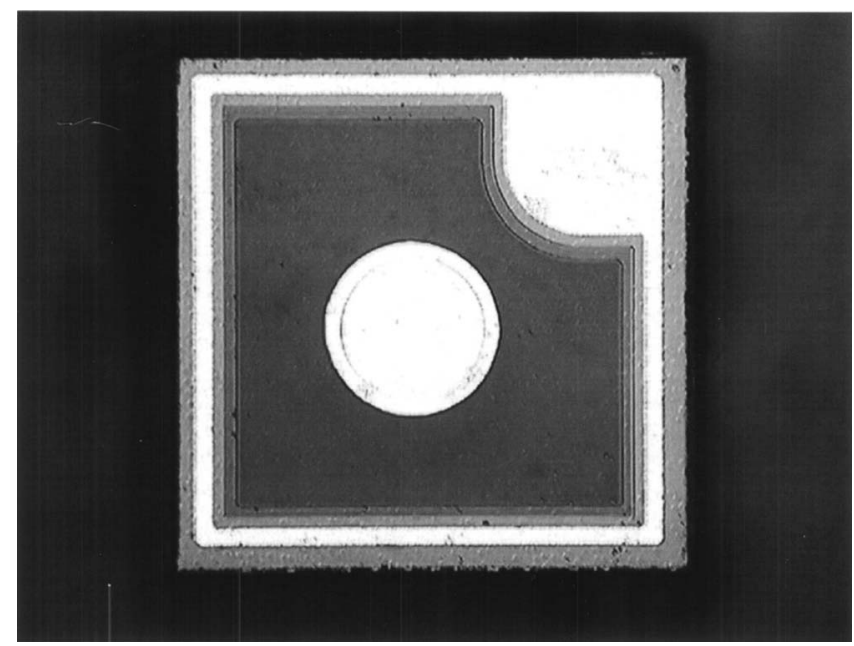

FIG. 1. Optical micrograph of the $410 \mathrm{~nm}$ LED die. The central circular contact is the $p$-metal while the surrounding area is the $n$-metal.

gamma rays is $>500 \mu \mathrm{m}$ in $\mathrm{GaN}$ and sapphire and therefore the radiation traverses the entire epi structure and the sapphire substrate. The irradiated devices were measured approximately 7 days after exposure. The forward and reverse current-voltage $(I-V)$ characteristics before and after irradiation were measured at $25^{\circ} \mathrm{C}$ on an Agilent $4165 \mathrm{C}$ parameter analyzer with the die heat-sink on a probe station. The optical output intensity with fixed LED placement in the test fixture was recorded at room temperature with an emission spectrometer.

As an example of the effect of high $\gamma$-ray doses, Fig. 2 shows the time dependence of forward voltage (defined as the voltage at which the current density is $50 \mathrm{~mA} / \mathrm{cm}^{2}$ ) from $410 \mathrm{~nm}$ diodes, both before and after irradiation up to $500 \mathrm{MRad}(\mathrm{Si})$. We measured the forward voltage as a function of time with bias applied to check for any postirradiation annealing effects that might occur. The forward voltage was increased only slightly $(\sim 0.1-0.15 \mathrm{~V})$ by the $\gamma$-ray exposure at doses of 250-500 MRad. Similar results were obtained from the LEDs of longer wavelengths. The ideality factor of all the LEDs was $\geqslant 2$ even prior to $\gamma$ irra-

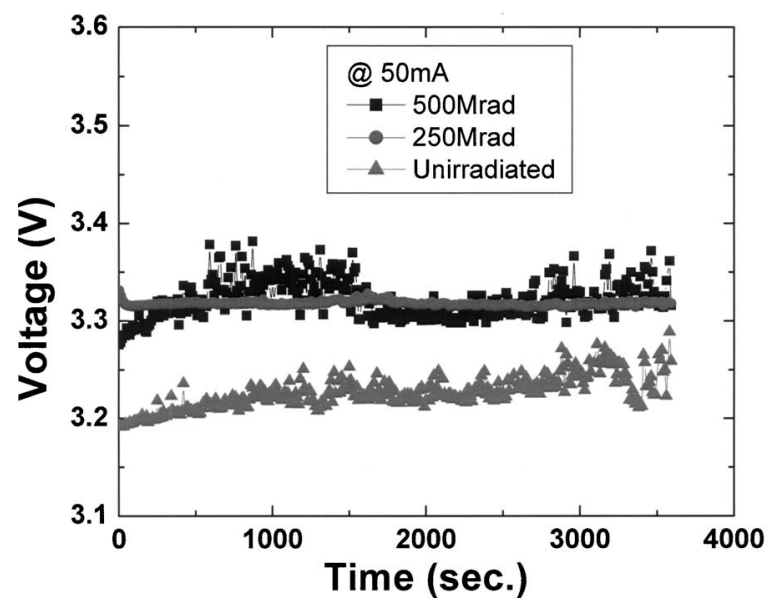

FIG. 2. Variation of forward turn-on voltage in $410 \mathrm{~nm}$ LEDs as a function of measurement time after various ${ }^{60} \mathrm{Co} \gamma$-ray doses. Turn-on voltage is defined as the voltage at which the forward current is $50 \mathrm{~mA} / \mathrm{cm}^{2}$. The data for the unirradiated diodes are from a total of 15 die whose data are overlapped, for the $250 \mathrm{MRad}$ samples there were 6 die and for the $500 \mathrm{MRad}$ samples there were 18 die.

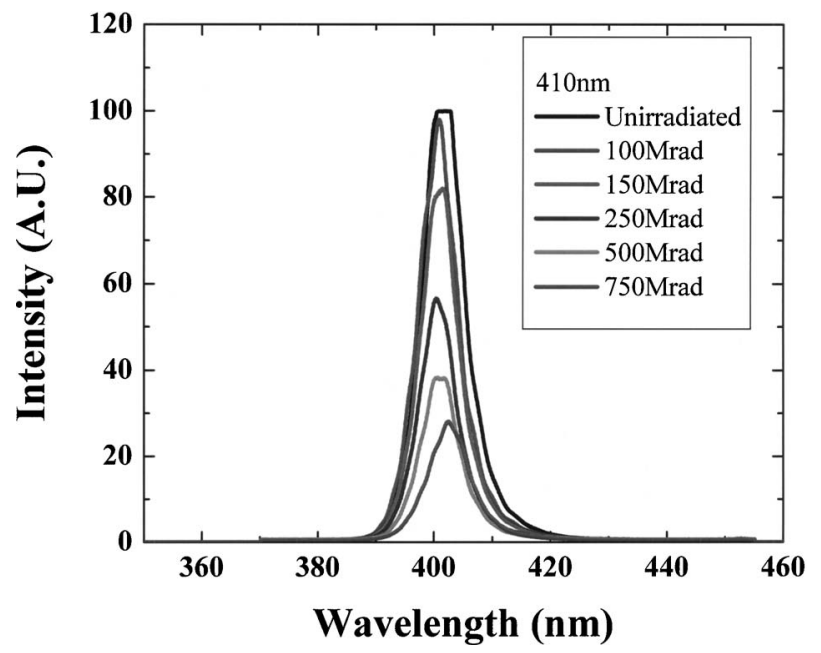

FIG. 3. Emission spectra from $410 \mathrm{~nm}$ LEDs as a function of ${ }^{60} \mathrm{Co} \gamma$-ray doses. The forward voltage was held constant at $3.5 \mathrm{~V}$ during the measurement.

diation, indicating that recombination is the dominant transport mechanism. The forward voltage $\left(V_{F}\right)$ of the $p-i-n$ junction can be written in terms of the applied voltage $V_{A}$ as $V_{F}=V_{A}-V_{B}$, where $V_{B}$ is the built-in voltage given by $V_{B}$ $=(e / 2 \varepsilon) / N_{D} x_{d}^{2}+/ N_{A} x_{a}^{2}$. In the latter equation, $e$ is the electronic charge, $\varepsilon$ is the dielectric constant, $N_{D, A}$ and $x_{d, a}$ are the donor (acceptor) concentrations and depletion depths in the two end regions of the $p^{+}-n-n^{+}$(the $p^{+}-n$ and $n^{+}-n$ regions). ${ }^{29,30}$ In a typical LED, the forward current includes terms from the diffusion recombination and tunnel currents. The small increase in turn-on voltage as a result of $\gamma$-ray irradiation may be due to several factors, including a decrease in the hole concentration on the $p$-side of the junction through creation of deep hole traps and introduction of shallow donors such as nitrogen vacancies. Even though $\gamma$ rays are not directly ionizing, they can lead to atomic displacements through secondary effects. Surface effects are less likely due to the very long range of the $\gamma$ rays, in this case longer than the thickness of the die, so that a uniform damage path is expected.

Figure 3 shows the change in output light intensity measured from the electroluminescence (EL) spectra before and after irradiation, as a function of the total $\gamma$-ray dose for the $410 \mathrm{~nm}$ LEDs. The forward voltage was held constant at $3.5 \mathrm{~V}$ during the measurement. Note that the decrease in light output in our case is intrinsic to the unpackaged InGaN/GaN structure and not to extrinsic factors such as degradation of the epoxy lens package which is known to degrade during reliability testing experiments. ${ }^{31}$ The longer wavelength LED showed similar degrees of light output degradation with dose and all were still functional with $\sim 25 \%$ of the initial emission intensity after a dose of $\sim 2$ GRad. Therefore, the In-content in the quantum well active regions does not appear to influence the radiation hardness of the LEDs over the range available to us. The appearance and morphology of both the $n$ - and $p$-metallization was also unchanged by the irradiation up to the maximum dose.

The reverse bias breakdown voltage (defined as the voltage at which the reverse current density is $1 \mathrm{~mA} \mathrm{~cm}^{-2}$ or a reverse current of $\sim 1 \mu \mathrm{A}$ ) of the LEDs was not degraded by any of the doses we investigated. Figure 4 shows the dependence of reverse breakdown voltage on dose for all four 


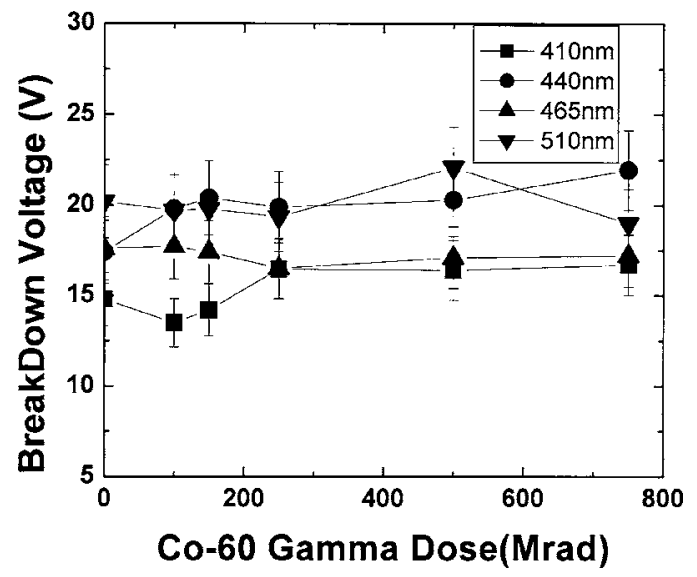

FIG. 4. Variation of reverse breakdown voltage in 410, 440, 465, and $510 \mathrm{~nm}$ LEDs as a function of ${ }^{60} \mathrm{Co} \gamma$-ray dose.

wavelength LEDs investigated. Within experimental error there was no change for any of our conditions. Moreover, the reverse current density was essentially unchanged, indicating minimal change in carrier density or mobility as a result of the irradiation. This suggests that the main degradation mechanism is introduction of nonradiative centers at a low enough density that they do not significantly affect the electrical properties.

In conclusion, $\gamma$-irradiated GaN/InGaN MQW LEDs exhibit very small increases in forward voltage even after total doses of $\sim 2$ GRad. Their electroluminescence characteristics are more affected by the irradiation (losing about a factor of 4 intensity at extremely high doses), suggesting that the main degradation mechanism is creation of recombination centers. These devices appear well-suited for both aerospace and terrestrial applications where radiation hardness up to total gamma-ray doses of $250 \mathrm{MRad}$ is a prerequisite. Future work may involve radiation exposure during a powered on-state, which would be of interest since this would perhaps initiate new degradation mechanisms.

The work at UF is partially supported by AFOSR grant under Grant No. F49620-03-1-0370, by the Army Research Office under Grant No. DAAD19-01-1-0603, NSF (CTS0301178, monitored by Dr. M. Burka and Dr. D. Senich) and the National Science Foundation (DMR 0400416, Dr. L. Hess). This work was also supported from the postdoctoral fellowship program of Korea Science and Engineering Foundation and Samsung Electro-Mechanics.

\footnotetext{
${ }^{1}$ See, for example, Introduction to Solid-State Lighting, edited by A. Zukauskas, M. S. Shur, and R. Gaska (Wiley, New York, 2002).

${ }^{2}$ Introduction to Nitride Semiconductor Blue Lasers and Light-Emitting Diodes, edited by S. Nakamura and S. F. Chichibu (Taylor and Francis, London, 2000).

${ }^{3}$ X. A. Cao and S. D. Arthur, Appl. Phys. Lett. 85, 3971 (2004).
}

${ }^{4}$ X. A. Cao, S. F. LeBoeuf, M. P. D’Evelyn, S. D. Arthur, J. Kretchmer, C. H. Yan, and Z. H. Yang, Appl. Phys. Lett. 84, 4313 (2004).

${ }^{5}$ T. Mukai, S. Nagahama, N. Iwasa, M. Senoh, and T. Yamada, J. Phys.: Condens. Matter 13, 7089 (2001).

${ }^{6}$ X. A. Cao, J. M. Teetsov, M. P. D'Evelyn, D. W. Merfeld, and C. H. Yan, Appl. Phys. Lett. 85, 7 (2004).

${ }^{7}$ A. Yasan, R. McClintok, K. Mayes, S. R. Darvish, P. Kung, M. Razeghi, and R. J. Molnar, Opto-Electron. Rev. 10, 287 (2002).

${ }^{8}$ D. D. Koleske, A. J. Fischer, A. A. Allerman, C. C. Mitchell, K. C. Cross, S. R. Kurtz, J. J. Figiel, K. W. Fullmer, and W. G. Breiland, Appl. Phys. Lett. 81, 1940 (2002).

${ }^{9}$ M. Khizar, Z. Y. Fan, K. H. Kim, J. Y. Lin, and H. X. Jiang, Appl. Phys. Lett. 86, 173504 (2005).

${ }^{10}$ M. L. Nakarmi, K. H. Kim, M. Khizar, Z. Y. Fan, J. Y. Lin, and H. X. Jiang, Appl. Phys. Lett. 86, 092108 (2005).

${ }^{11}$ Y. Xi, J.-Q. Xi, Th. Gessmann, J. M. Shah, J. K. Kim, E. F. Schubert, A. J. Fischer, M. H. Crawford, K. H. A. Bogart, and A. A. Allerman, Appl. Phys. Lett. 86, 031907 (2005).

${ }^{12}$ J. P. Zhang, X. Hu, Yu. Bilenko, J. Deng, A. Lunev, M. S. Shur, R. Gaska, M. Shatalov, J. W. Yang, and M. A. Khan, Appl. Phys. Lett. 85, 5532 (2004).

${ }^{13}$ K. Mayes, A. Yasan, R. McClintock, D. Shiell, S. R. Darvish, P. Kung, and M. Razeghi, Appl. Phys. Lett. 84, 1046 (2004).

${ }^{14}$ K. H. Kim, Z. Y. Fan, M. Khizar, M. L. Nakarmi, J. Y. Lin, and H. X. Jiang, Appl. Phys. Lett. 85, 4777 (2004).

${ }^{15}$ A. Yasan, R. McClintock, K. Mayes, D. Shiell, L. Gautero, S. R. Darvish, P. Kung, and M. Razeghi, Appl. Phys. Lett. 83, 4701 (2003).

${ }^{16}$ V. Adivarahan, W. H. Sun, A. Chitnis, M. Shatalov, S. Wu, H. P. Maruska, and M. Asif Khan, Appl. Phys. Lett. 85, 2175 (2004).

${ }^{17}$ V. Adivarahan, S. Wu, W. H. Sun, V. Mandavilli, M. S. Shatalov, G. Simin, J. W. Yang, H. P. Maruska, and M. Asif Khan, Appl. Phys. Lett. 85, 1838 (2004).

${ }^{18}$ H. Peng, E. Makarona, Y. He, Y.-K. Song, A. V. Nurmikko, J. Su, Z. Ren, M. Gherasimova, S.-R. Jeon, G. Cui, and J. Han, Appl. Phys. Lett. 85, 1436 (2004).

${ }^{19}$ K. B. Nam, J. Li, M. L. Nakarmi, J. Y. Lin, and H. X. Jiang, Appl. Phys. Lett. 84, 5264 (2004).

${ }^{20}$ A. J. Fischer, A. A. Allerman, M. H. Crawford, K. H. A. Bogart, S. R. Lee, R. J. Kaplar, W. W. Chow, S. R. Kurtz, K. W. Fullmer, and J. J. Figiel, Appl. Phys. Lett. 84, 3394 (2004).

${ }^{21}$ G. Zorpette, IEEE Spectrum Online, May 9, 2005.

${ }^{22}$ M. Osinski, P. Perlin, H. Schone, A. H. Paxton, and E. W. Taylor, Electron. Lett. 33, 1252 (1997).

${ }^{23}$ R. Khanna, K. Allums, C. R. Abernathy, S. J. Pearton, J. Kim, F. Ren, R. Dwivedi, T. N. Fogarty, and R. Wilkins, Appl. Phys. Lett. 85, 3131 (2004).

${ }^{24}$ F. Gaudreau, C. Carlone, A. Houdayer, and S. M. Khanna, IEEE Trans. Nucl. Sci. 48, 1778 (2001).

${ }^{25}$ A. Ionascut-Nedelcescu, C. Carlone, A. Houdayer, H. J. von Bardeleben, J. L. Cantin, and S. Raymond, IEEE Trans. Nucl. Sci. 49, 2733 (2002).

${ }^{26}$ S. M. Khanna, D. Estan, L. S. Erhardt, A. Houdayer, C. Carlone, A. Ionascut-Nedelcescu, S. R. Messenger, R. J. Walters, G. P. Summers, J. H. Warner, and Insoo Jun, IEEE Trans. Nucl. Sci. 51, 2729 (2004).

${ }^{27}$ C. Li and S. Subramanian, IEEE Trans. Nucl. Sci. 50, 1998 (2003).

${ }^{28}$ S. M. Khanna, D. Estan, A. Houdayer, H. C. Liu, and R. Dudek, IEEE Trans. Nucl. Sci. 51, 3585 (2004).

${ }^{29}$ H. Hirayama, J. Appl. Phys. 97, 091101 (2005).

${ }^{30}$ M. Fukuda, Reliability and Degradation of Semiconductor Lasers and LEDs (Artech House, Boston, 1991).

${ }^{31}$ M. Osinski and D. L. Barton, in Introduction to Nitride Semiconductor Blue Lasers and Light-Emitting Diodes, edited by S. Nakamura and S. F. Chichibu (Taylor and Francis, London, 2000), Chap. 6. 